DOI: $10.17805 /$ ggz.2020.3.3

\title{
Оптико-механические средства воспроизведения действительности как конкуренты традиционного искусства
}

\author{
А. Н. Севастьянов
}

Московский гуманитарный университет

В статье отмечается, что к решающему перевороту искусство влекли не только психологические и идейные, но и обусловленные прогрессом науки и техники обстоятельства. Показано, как технологии физионотраса, дагеротипа и фотографии изменили художественные средства отражения действительности.

Ключевые слова: искусство; физионотрас; дагеротип; фотография; техника; средства художественной выразительности

\section{Optical and Mechanical Means of Reality Reproduction as Competitors of Traditional Art}

A. N. Sevastianov

Moscow University for the Humanities

The article points out that not only psychological and ideological circumstances were leading to radical changes in art, but also those that were conditioned by the progress in science and technics. It is shown that technologies of physiognotrace, daguerreotype and photography changed artistic means of reality reflection.

Keywords: art; physiognotrace; daguerreotype; photography; technics; means of artistic expression

\section{ВВЕДЕНИЕ}

В высшей степени знаменательным для искусства стал факт, который никак не назовешь случайным: свою первую громкую объединенную выставку (165 работ 30 художников), независимо от Салона, импрессионисты провели не где-нибудь, а в огромном трехэтажном ателье знаменитого фотографа Надара, «великого Надара», в самом центре Парижа. Так фотография и импрессионизм объединились заодно, чтобы дать бой старому, подвести под ним черту. Импрессионисты не хотели больше соперничать с фотографией в копировании Природы, как это делали - или пытались делать - мэтры салонной живописи. Они уже вполне оценили бессмысленность этого занятия и 
демонстративно ему изменили. И это, конечно же, - столь важное знамение времени, что о нем стоит сказать подробнее.

Дело в том, что те два великих принципа, на которых стояло искусство от истоков - воспевание Божьего творения (а через то - самого Творца) и демонстрация мастерства — в равной мере требовали от художника наиточнейшего воспроизведения Природы, во всем следуя завету правдоподобия. И самым великим мастерам это удавалось наиболее виртуозно. Отличное представление об этом дают, например, живописные портреты Альбрехта Дюрера, при рассмотрении которых общее мощное впечатление от точно схваченного характера модели и всех ее физических и моральных особенностей сочетается с изумлением, которое при тщательном разглядывании вызывает мелочная подробность и искусность, с какой выписана каждая шерстинка на меховом воротнике или волосинка в бороде и кудрях. Превзойти в этом Дюрера не удавалось никому — но подражать-то стремились все! Так же тщательно выписывались, скажем, на голландских натюрмортах (взять хоть Герарда Доу) листочки и лепесточки, пористый хлеб, капельки росы, усики жуков и бабочек, чешуйки ящерок и змеек, а на портретах Иоганна Тишбейна или Каспара Нетшера - атлас и бархат, бронза и полированное дерево, пуговки и ленточки, гребни из панциря черепахи, ювелирные украшения и т. п. Можно сказать, что все эти великие мастера творили с фотографической для своего времени точностью и видели в том важное художественное достоинство.

В своем стремлении точно запечатлеть натуру художники нередко прибегали к более или менее простым приборам, порой самостоятельно изобретенным. Так, в книге того же Дюрера об измерениях в искусстве мы видим на гравюрах-иллюстрациях, как художник использует различные приспособления для наиболее точного воспроизведения модели в портрете или натюрморте. В том числе - что для нас особенно важно - с использованием стеклянной призмы и рамки.

Стремление быть максимально точным в уподоблении натуре привело даже к такому своеобразному жанру, как «обманки» - т. е. картины (именно натюрморты), которые должны были создавать у зрителя полную иллюзию реальности. Особое внимание при этом, конечно, уделялось фактуре изображаемых предметов - бумаги, древесины, воды в стеклянных емкостях и т. д.

В России этот жанр был весьма популярен (прекрасные образцы можно видеть, например, в музее-усадьбе «Кусково»). И даже дал своего рода гения - великого художника-любителя графа Федора Толстого, чью «чудотворную кисть» упоминает в своих стихах Пушкин.

Однако, как пророчески написал тот же Пушкин, «но примешь ты смерть от коня своего». Развитие оптико-механических приборов, призван- 
ных вначале помогать художнику, привело постепенно к тому, что прибор в итоге выбил художника с поля, на котором веками происходила конкуренция за верное изображение окружающей действительности. Это произошло в несколько этапов.

\section{ФИЗИОНОТРАС}

Вначале появилась техника под названием «физионотрас» - что в переводе с французского значит «след лица». Это первая попытка использовать оптико-механическое устройство для скрупулезно верной передачи натуры, а именно человеческой физиономии.

Физионотрасом первоначально назвали техническое устройство, изобретенное французским музыкантом-виолончелистом Жилем-Луи Кретьеном в 1784 г. (Hennequin, 1932). Оно представляло собой деревянную кабину, куда неподвижно усаживали портретируемого, направляя при этом на него пучок света таким образом, чтобы на экране запечатлелся точный абрис лица в профиль. А в это время оператор (портретист), стоя позади экрана, переводил этот профиль в уменьшенном виде на лист бумаги с помощью специального аппарата - пантографа с визиром (прицелом). Все делалось очень быстро, буквально за пять минут. После чего рисунок, заключенный обычно в круглую рамку диаметром около 6 см, переносился на медную доску, чтобы быть протравленным в технике офорта ${ }^{1}$. Но физионотрас, в отличие от популярных в ту эпоху профильных «силуэтов», обычно залитых черным тоном на светлом фоне, представлял собой не просто контур, а заполнялся рисовальщиком-изготовителем так, что появлялись тени, формирующие объем: глаза, ноздри, уши, губы, волосы и т. д. — как в обычном гравированном портрете.

Нельзя сказать, чтобы такой физионотрас отличался в лучшую строну от простого портрета в профиль, выполненного умелым художникомофортистом, таким, как Николя Кошен или Огюстен Сент-Обен (большие мастера в этом жанре). Но, во-первых, все делалось очень быстро и стоило сравнительно недорого. А во-вторых, у заказчика возникала полная иллюзия, что уж при таком техническом оснащении не будет и малейшей погрешности, и что родные и близкие получат его изображение «один в один» схожее с оригиналом - пусть только в профиль, но зато вернейшее.

\footnotetext{
${ }^{1}$ Офорт - самая свободная и творческая из всех техник гравирования на металле (т. н. глубокая печать), по сути просто размноженный рисунок. Только художник рисует не карандашом или пером на бумаге, а специальной иглой на медной доске, покрытой кислотоупорным лаком. Процарапав лак до самой поверхности металла, он травит затем доску кислотой, которая, проникая сквозь царапины, вытравливает в металле бороздки. В них потом, после стирания лака, набивается краска, которая при тиснении переходит на увлажненную бумагу — и получается гравюра.
} 
Через несколько дней отпечатанная с медной доски и высушенная дюжина бумажных копий (больше не делалось принципиально) вручалась заказчику, а все оригиналы - гравированные доски - сохранялись в собственности изготовителя. Такие бумажные копии тоже стали называться физионотрасами.

Изобретатель новой техники Жиль Кретьен первые четыре года использовал физионотрас только для портретирования своих друзей и родных, но в 1788 г. он создает совместно с Эдвардом Кенедеем, англичанином, совместное предприятие недалеко от Версаля, сняв студию и разместив в газетах объявление. Успех был огромным: в первый же год примерно тысяча клиентов пожелали иметь свой портрет, изготовленный почти мгновенно новым, «прогрессивным» способом. У Кретьена и Кенедея перебывал весь парижский свет; сохранились физионотрасы ряда знаменитостей: королевской семьи, Жильбера Лафайета, Оноре Мирабо, Жан-Поля Марата. Но имеется также множество портретов людей попроще, мужчин и женщин, начиная с придворных, офицеров и чиновников и заканчивая простолюдинами. До нас дошли даже изображения русских офицеров из числа тех, что брали Париж в 1814 г., ведь многим хотелось вернуться домой в Россию с таким портретом - свидетельством торжества русского оружия и памятью о славных парижских деньках...

Со временем Кенедей и Кретьен рассорились, их совместное предприятие распалось, и Кенедей отправился путешествовать по свету с портативным физионотрасом. Сохранились работы, сделанные им в Бельгии и Германии, Италии и Австрии, и даже России (в том числе портреты Василия Жуковского и Льва Пушкина) и Америке (в Библиотеке конгресса США хранится около ста портретов видных политиков, в том числе физионотрас первого президента США Джорджа Вашингтона). Искусство физионотраса продержалось всю первую треть XIX в., пока его не вытеснил дагеротип. Самыми поздними считаются портреты французских великих писателей: Виктора Гюго, Стендаля и Александра Дюма-отца.

Всего известно более пяти тысяч портретов разных лиц, сделанных подобным способом; это - на два порядка более значимая цифра, чем мог бы создать художник-гравер, работая офортом, а тем более резцом (на одну портретную гравюру большого формата уходили порой месяцы, а то и годы жизни ${ }^{2}$ ). Пусть тиражи физионотрасов были маленькими, зато вовлеченность в процесс столь большого количества людей - беспрецедентна. Ничего подобного раньше не было.

\footnotetext{
${ }^{2}$ К примеру, парадный портрет русской императрицы Анны Иоанновны гравер Кристиан Вортман создавал в течение трех лет.
} 
Перед нами — что очень важно отметить! - первый явный выход масс на сцену в качестве непосредственного заказчика искусства И, таким образом, - первые шаги массового искусства: явление, последствия которого оказались колоссальны.

\section{ДАГЕРОТИП}

Как говорится, лиха беда - начало. Если общественная потребность созрела, она так или иначе будет удовлетворена. Поначалу, заметим, этот новый спрос обслуживали всего-навсего два человека, Жиль Кретьен и Эдвард Кенедей. Но вскоре на смену физионотрасу приходят новые оптикомеханические техники массового искусства, причем несравненно более точные в плане копирования реальности. Поскольку рукотворного вмешательства от художника требовалось все меньше и меньше: все делали за него оптические аппараты и химические препараты. Зато адептов нового способа воспроизведения действительности становилось все больше и больше.

Избегая подробного очерка истории фотографии, отметим только основные даты и события в ходе возникновения у традиционного искусства убийственно успешного конкурента.

Искусство фотографии произошло от слияния достижений в области физики (оптики) и химии. Предшественником фотокамеры была так называемая «камера-обскура» (лат. camera obscūra - «темная комната»), представлявшая собой, как повествует Википедия, «светонепроницаемый ящик с отверстием в одной из стенок и экраном (матовым стеклом или тонкой белой бумагой) на противоположной стене. Лучи света, проходя сквозь малое отверстие (постоянная “дифрагма” камеры, обычно ее диаметр составляет приблизительно 0,1-5 мм) создают перевернутое изображение на экране» (Камера-обскура, б/д: Электронный ресурс). Первым использовал такой аппарат для зарисовок с натуры Леонардо да Винчи, подробно описавший его в своем «Трактате о живописи».

В начале XVII в. Иоганн Кеплер открыл законы преломления света, использованные впоследствии Галилео Галилеем при изготовлении телескопа. В результате подобных изысканий камера-обскура со временем последовательно оснащалась зеркалами, матовым стеклом, линзами и объективами... Это позволяло с большой точностью копировать пейзажи, портреты, натюрморты на бумагу. Но все равно, без ручного труда художника обойтись было пока еще невозможно.

В 1807 г. английский химик и физик Уильям Хайд Волластон изобрел также «камеру-люциду» (от лат. “lux” — «свет»), где четырехгранная призма помогала совместить изображение пейзажа с листом бумаги, на котором его фиксировал художник. 
Однако только новые открытия химиков привели к появлению фотографических снимков. По легенде, впервые закрепленное изображение было получено в 1822 г., но оно до наших дней не сохранилось. Его автор, французский изобретатель Жозеф Нисефор Ньепс, через четыре года, в 1826 г., получил с использованием камеры-обскуры на покрытой тонким слоем асфальта оловянной пластинке снимок «Вид из окна в Ле Гра», который дошел до нас в качестве первообразца. Он абсолютно малохудожествен.

Далее прогресс в новом деле шел крещендо, попытки множились. Википедия сообщает: «...в 1833 году метод получения фотографии при помощи нитрата серебра опубликовал франко-бразильский изобретатель и художник Эркюль Флоранс. Свой метод он не запатентовал, и о его исследованиях стало известно лишь в 1970-х годах» (Фотография, б/д: Электронный ресурс). Как пишет С. Голубев, «в 1835 году англичанин Уильям Генри Фокс Тальбот изобрел способ получения негативного фотографического изображения на бумаге, пропитанной хлористым серебром, который назвал калотипией. В 1839 году, уже после смерти Ньепса, другой француз, художник и химик Луи-Жак Дагер выступил на заседании Французской Академии с докладом о способе получения изображения на медной пластине, покрытой серебром дагеротипии» (Голубев, 2013: 97). Название «фотография» (дословно «светопись»] выбрали члены Французской академии в 1839 г., посчитав его наиболее благозвучным. Были и другие параллельные изобретения, что само по себе свидетельствует о том, что задача назрела.

Само слово «фотография» было одновременно использовано в том же году двумя астрономами - англичанином Джоном Гершелем и немцем Иоганном фон Медлером независимо друг от друга (там же). Но в течение долгого времени первообразцы, создававшиеся, как правило, на металле или стекле, именовались по имени изобретателя Луи Дагера - «дагеротипами». Дагер использовал сложную технологию, применял пары йода и ртути, закрепляя результат поваренной солью. Экспозиция поначалу требовала длительного времени - от 30 минут до часу. Свое изобретение Дагер, не сумевший сделать его прибыльным, продал правительству Франции, получив ежегодную пенсию в 6000 франков.

Дагеротипия начала с огромной скоростью завоевывать мир. Характерно, что вначале, уже в сентябре 1839 г. дагеротип появился в США, в НьюЙорке. Следом, как ни странно, - в России: в октябре того же года подполковник путей сообщения Теремин получил снимок Исаакиевского собора в Петербурге.

Поскольку для снимка требовалась поначалу очень большая выдержка, то в первое время считалось невозможным дагеротипическое портретирование. Но уже в 1840 г. американец Джон Дрейпер смог с выдержкой всего в 65 
секунд сделать портрет своей сестры при ярком солнечном свете. А дальше - дагеротип успешно принял на себя те функции, которые до него начал было осуществлять физионотрас.

Неудивительно, что первенствовать в этом деле сразу же стала Америка, сделавшаяся к тому времени не только эпицентром «восстания масс», но и олицетворением этого глобального процесса. Коммерция на почве портретной дагеротипии расцвела здесь мгновенно и самым пышным цветом. В начале марта 1840 г. в Нью-Йорке открылось первое в мире портретное фотоателье (голова портретируемого, чтобы снимок был четким, закреплялась специальным держателем - копфгальтером). Вскоре светосильная оптическая схема позволила уменьшить выдержку с 30 минут у первых фотоаппаратов до 5 у «зеркального», а всего через год выдержка при портретной съемке составила всего 1 секунду. К середине 40-х годов XIX в. началось распространение дагеротипных фотоателье по всему миру, а в США появился внимание! - даже целый городок Дагеровиль с большим количеством портретных студий.

О небывалых возможностях и небывалой популярности нового способа воспроизведения действительности свидетельствует такой факт: за один только 1847 год в одном только Париже было продано полмиллиона (!) пластин с идеально отполированной серебряной поверхностью для изготовления дагеротипа. По сравнению даже с пятью тысячами физионотрасов, созданных в общей сложности к началу 1830-х гг, это просто космический взлет массовости. Производство нового типа художественных изображений росло неудержимо и лавинообразно, вытесняя художников из их родной и казавшейся вековечной ниши. Процесс явно коррелировал с ширящимся «восстанием масс».

При этом в ход шла уже и новая техника гальванизации, когда тонкий слой серебра осаждался на электрод - отшлифованный медный или латунный лист. В России такой способ изготовления впервые был предложен гениальным русским изобретателем Алексеем Грековым в 1840 г. Тогда же он придумал упрочивать дагеротипные изображения, гальванически нанося на пластины тончайший слой золота. Вскоре Греков первым в России стал применять «фотографию» в полиграфии: в том же 1840 г. он научился производить оттиски дагеротипов на бумаге с помощью техники плоской печати (прообраз современного офсета). В дальнейшем Греков экспериментировал со светочувствительной бумагой. Его имя прославилось не только в петербургских, но и в парижских и немецких специальных изданиях ${ }^{3}$. ${ }^{3}$ В 1843 г. Греков переехал в Петербург, где получил должность начальника типографии
губернского правления, а в 1844 г. опубликовал монографию о гальванопластике. Однако, 
Он же стал и первым русским фотографом-портретистом, и первым в России стал изготавливать приборы для дагеротипии. В июне 1840 г. Греков открыл «художественный кабинет», где можно было сделать портрет «величиной с табакерку», а годом позже выпустил брошюру, в которой впервые пропагандировал «художественные аспекты фотографии» (Греков ... , б/д: Электронный ресурс). История русской фотографии как искусства ведет свой отсчет с этой даты.

Несмотря на изобретения Грекова, дагеротип, однако, изготавливался только в одном экземпляре и не предусматривал тиражирования изображений. В этом смысле он отличался от физионотраса, печатавшегося обычно хотя бы в дюжине экземпляров. И эту бестиражность, конечно, необходимо было преодолеть.

\section{ФОТОГРАФИЯ}

Между тем изобретение фотографии продолжало эволюционировать, решая по пути одну задачу за другой. Тут первое слово принадлежало химикам, придумавшим вначале альбуминовую фотобумагу (1850), потом бумагу целлоидиновую или колодионовую (промышленный выпуск с 1884), потом платиновую (1887), желатиносеребряную и т. д. С 1879 г. производство фотобумаги уже было поставлено на конвейер. В ходу были также фотопластины - стекла со светочувствительным слоем.

Художественные возможности фотографии быстро были осознаны и самими фотографами, и обществом, и - что особенно важно - художниками. Выше уже упоминался знаменитый парижский фотограф Надар (настоящее имя Гаспар-Феликс Турнашон, 1820-1910), давший приют первой выставке импрессионистов в 1874 г. Его искусство к этому времени принесло ему уже не только славу (его прозвали «Тицианом фотографии»), но и состояние. Сделанные им портреты получали известность, ему позировали знаменитости, прославленный живописец Жан Огюст Доминик Энгр прибегал к его помощи, предпочитая рисовать по фотографии, чтобы не утруждать модель ${ }^{4}$. Надар делился секретом своего успеха: «Чтобы получить сходство, а не банальный портрет, вы должны вступить в союз с позирующим, почув-

как пишет Википедия, судьба русского гения сложилась трудно: до конца дней Греков «пытался выплатить огромный долг, который у него оказался перед московской типографией в результате многочисленных опытов и экспериментов. Ни книги, ни художественный салон, который не выдержал конкуренции с множеством фотоателье, открытых в столице иностранцами, не помогли ему полностью расплатиться по долгу. После смерти Грекова в 1855 году его вдова оставалась в долгу перед типографией» (Греков ..., б/д: Электронный ресурс).

${ }^{4}$ Первым стал использовать фотографию для создания своих композиций импрессионист Эдгар Дега. 
ствовать его мысли и сам его характер» (см.: Надар, б/д: Электронный ресурс). Разве это не принцип истинного художника? Положим, Надар был один такой, но художников-фотографов рангом немного пониже имелось уже достаточно; люди Запада умеют не упускать возможности заработать.

Процесс шел все дальше. В 1880 г. американец Джордж Истмен изобретает сухую желатиновую фотоэмульсию, которая наносилась на негативные пластинки. В 1889 г. он же первым получил патент на фотопленку с целлулоидной подложкой в рулоне (целлулоид производился промышленно уже с 1870 года), а через некоторое время и на фотокамеру «Кодак», разработанную специально для работы с рулонной фотопленкой. С этого, собственно говоря, и следует отсчитывать историю фотографии в современном смысле слова.

Между тем, уже в середине XIX столетия появились и первые цветные фотоснимки по методу цветоделения (первый такой трехцветный снимок был сделан в 1861 г. Джеймсом Максвеллом с трех фотокамер одновременно). Но фотокамера для трехцветной съемки и трехлучевой проектор для демонстрации полученных цветных снимков были изобретены на полвека позже немецким ученым Адольфом Мите, продемонстрировавшим новое оборудование в Берлине в 1902 г. Русский ученик Мите - Сергей Прокудин-Горский - значительно усовершенствовал изобретение и оставил потомкам серии великолепных цветных фотографий, запечатлевших виды дореволюционной России. А в 1907 г. знаменитые изобретатели кинематографа братья Люмьер запатентовали фотопластины «Автохром», позволявшие делать цветные фото относительно легко и быстро. Их изобретение поступило в свободную продажу и закрепило всемирный технический переворот в фотоделе: до 1935 г. в мире было уже изготовлено 50 млн автохромных пластинок.

Массовое искусство, вызванное к жизни «восстанием масс», встало на почетное место и на поточное производство. Теперь своего рода художником - с помощью фотокамеры - мог стать вообще каждый желающий.

Изобретение фотографии имело еще одно очень важное последствие, также вплотную приближавшее восставшие массы к искусству (и наоборот, его к ним). Это изобретение фотомеханических способов типографского воспроизведения любых изображений, в том числе цветных, в книгах и альбомax, а пуще того - в газетах и журналах, выходивших уже многотысячными тиражами. На смену гравюре на стали, торцовой гравюре на дереве и литографии, дававшим десятки тысяч репродукций, пришли цинковые клише, растровая печать, выдерживавшая тиражи уже во многие сотни тысяч экземпляров. Электричество творило свои чудеса. То, что раньше требовало долгого, сложного и кропотливого труда талантливого художника-гравера или литографа, теперь достигалось усилиями фотографов и сотен мастеровых- 
печатников, обученных достаточно простым конвейерным процессам и обеспечивавших вал печатной продукции, обрушившейся на массового читателя по всему миру. Любая новинка в искусстве, как, впрочем, и любая старина, становилась тут же доступна всем и каждому, попадая в руки разносчиков прессы, в киоски и библиотеки.

Вторая и, особенно, Третья информационная революция в XIX столетии ${ }^{5}$ сделали искусство предметом всеобщего любопытства и обсуждения, резко стимулировали арт-рынок и необыкновенно подхлестнули амбиции художников.

\section{ЗАКЛЮЧЕНИЕ}

Появление и быстрый расцвет фотографии уже к концу XIX в. выбило почву из-под ног многих тысяч профессиональных художников - портретистов, пейзажистов, натюрмортистов, жанристов и т. д. Ибо обессмыслило всю традицию искусного подражания природе, копирования ее, а тем самым заставило живописца заново оценить суть своей профессии, по-новому взглянуть на свои задачи. Ведь конкурировать с фотографией по части детального подобия изображаемому - нелепо, такая задача была заведомо провальной, а претензия - заведомо несостоятельной. Выписывать часами, как когда-то Дюрер или Доу, травинки и листочки, шерстинки и волосики, капельки росы и т. п., когда все это можно куда точнее запечатлеть одним нажатием кнопки на фотокамере, теперь уж, конечно, честолюбивому художнику и в голову бы не пришло. Зачем?! Как ни старайся, фотографию в этом смысле «не переплюнешь».

Значит, нужно было искать новую - глубинную! - суть перенесения на холст или бумагу образов внешнего мира. Такую суть, которая была бы недоступна никакому, даже самому совершенному фотообъективу. Надлежало разграничить «зоны ответственности» фотографии и живописи.

Поиском этой сути и были обречены заниматься художники с 1860-х гг. - каждый в меру отпущенного ему дарования. Занятие, дотоле небывалое, сродни известному: «пойди туда, не знаю куда, принеси то, не знаю что». Первыми на этот путь, как уже говорилось, ступили импрессионисты, но те, кто шел за ними, должны были пойти гораздо дальше.

И в этом одна из наиболее существенных причин разразившегося с тех пор в искусстве кризиса.

\footnotetext{
${ }^{5}$ Первая — «революция печатной книги» — прошла в XV в., Вторая — «революция публики» — в первой трети XIX в. (см.: Севастьянов, 2013: 21-88).
} 


\section{СПИСОК ЛИТЕРАТУРЫ}

Голубев, С. (2013) Физионотрас: фотография до фотографии // Исторический журнал. № 12. С. 96-105.

Греков, Алексей Фёдорович (б/д) [Электронный ресурс] // Википедия: свободная энциклопедия. URL: https://ru.wikipedia.org/wiki/Греков,_Алексей Фёдорович [архивировано в WaybackMachine] (дата обращения: 17.04.2020).

Камера-обскура (б/д) [Электронный ресурс] // Википедия: свободная энциклопедия. URL: https://ru.wikipedia.org/wiki/Kамера-обскура [архивировано в WaybackMachine] (дата обращения: 17.04.2020).

Надар (б/д) [Электронный ресурс] // Википедия: свободная энциклопедия. URL: https://ru.wikipedia.org/wiki/Надар [архивировано в WaybackMachine] (дата обращения: 17.04.2020).

Севастьянов, А. Н. (2013) Битва цивилизаций: секрет победы. М. : Книжный мир. 208 с.

Фотография (б/д) [Электронный ресурс] // Википедия: свободная энциклопедия. URL: https://ru.wikipedia.org/wiki/Фотография [архивировано в WaybackMachine] (дата обращения: 17.04.2020).

Hennequin, R. (1932) Avant les photographies: Les portraits au physionotrace gravés de 1788 à 1830 : Catalogue nominatif, biographique et critique illustré des deux premières séries de ces portraits comprenant les 1800 estampes cotées de “1” à R 27. Troyes : J. L. Paton. 345 p.

Дата поступления: 20.04.2020 г.

\section{REFERENCES}

Golubev, S. (2013) Fizionotras: fotografiia do fotografii [Physiognotrace: Photography before photography]. Istoricheskii zhurnal, no. 12, pp. 96-105. (In Russ.).

Grekov, Aleksei Fedorovich (s.d.) Vikipediia: svobodnaia entsiklopediia [Wikipedia: The Free Encyclopedia] [online] Available at: https://ru.wikipedia. org/wiki/Греков,_Алексей_Фёдорович [archived in WaybackMachine] (accessed 17.04.2020). (In Russ.).

Kamera-obskura [Camera obscura] (s.d.) Vikipediia: svobodnaia entsiklopediia [Wikipedia: The Free Encyclopedia] [online] Available at: https://ru.wikipe dia.org/wiki/Камера-обскура [archived in WaybackMachine] (accessed 17.04. 2020). (In Russ.).

Nadar (s.d.) Vikipediia: svobodnaia entsiklopediia [Wikipedia: The Free Encyclopedia] [online] Available at: https://ru.wikipedia.org/wiki/Hадар [archived in WaybackMachine] (accessed 17.04.2020). (In Russ.). 
Sevastianov, A. N. (2013) Bitva tsivilizatsii: sekret pobedy [Battle of civilizations: Secret of victory]. Moscow : Knizhnyi mir Publ. 208 p. (In Russ.).

Fotografiia [Photography] (s.d.) Vikipediia: svobodnaia entsiklopediia [Wikipedia: The Free Encyclopedia] [online] Available at: https://ru.wikipedia.org/ wiki/Фотография [archived in WaybackMachine] (accessed 17.04.2020). (In Russ.).

Hennequin, R. (1932) Avant les photographies: Les portraits au physionotrace gravés de 1788 à 1830 : Catalogue nominatif, biographique et critique illustré des deux premières séries de ces portraits comprenant les 1800 estampes cotées de “1” à R 27. Troyes : J. L. Paton. 345 p. (In Fr.).

Submission date: 20.04.2020.

Севастьянов Александр Никитич — кандидат филологических наук, главный научный сотрудник Института фундаментальных и прикладных исследований Московского гуманитарного университета. Адрес: 111395, Россия, г. Москва, ул. Юности, 5. Эл. адрес: mail@sevastianov.com

Sevastianov Aleksandr Nikitich, Candidate of Philology, Chief Researcher, Institute of Fundamental and Applied Studies, Moscow University for the Humanities. Postal address: 5, Yunosti St., 111395 Moscow, Russian Federation. E-mail: mail@sevastianov.com

Для цุитирования:

Севастьянов А. Н. Оптико-механические средства воспроизведения действительности как конкуренты традиционного искусства [Электронный pecypc] // Горизонты гуманитарного знания. 2020. № 3. С. 21-32. URL: https://journals.mosgu.ru/ggz/article/view/1233 (дата обращения: дд.мм.гггг). DOI: 10.17805/ggz.2020.3.3 